\title{
Antropología y campesinado: la pertinencia de lo persistente. Reflexiones antropológicas en torno al internacionalismo campesino ${ }^{1}$
}

\author{
Anthropology and the peasant class: the pertinence of \\ the persistent. Anthropological reflections on peasant \\ internationalism
}

RAÚL H. CONTRERAS ROMÁN

Posgrado en Antropología, Universidad Nacional Autónoma de México

RECEPCIÓN: 30/O4/20I 5 • ACEPTACIÓN: 03/I 2/20I 5

\begin{abstract}
RESUMEN En el presente artículo se elabora una discusión inicial respecto de la persistencia del campesinado en la antropología como objeto incómodo, que desde su irrupción en la disciplina ha obligado a ésta a rediscutir su identidad disciplinaria y a repensar su cuerpo teórico. Se parte de la idea que tanto la emergencia como el ocaso de los estudios campesinos en la disciplina se corresponden con contextos sociales, intelectuales y políticos localizables. Por ello se presenta la actual lucha del internacionalismo campesino, representado por el movimiento transnacional Vía Campesina, en torno a la soberanía alimentaria y el reconocimiento internacional de los derechos de los campesinos y campesinas. Se considera que estas luchas constituyen un espacio políticamente novedoso y potencialmente generador de oportunidades políticas para las reivindicaciones campesinas frente al despojo neoliberal. Finalmente, se reflexiona en torno a cómo estas luchas vuelven a presentar al campesinado como un objeto incómodo para la antropología y
\end{abstract}

I. El presente artículo fue escrito con el apoyo del Programa de Becas para Estudios de Posgrado de la Universidad Nacional Autónoma de México. 
a reclamar la discusión disciplinaria sobre este sector.

PALABRAS CLAVE Campesinado, antropología, cuestión agraria, movimiento social, Vía Campesina, soberanía alimentaria, Derechos Humanos.

ABSTRACT The present article develops an initial discussion on the persistence of the peasant class in anthropology as an awkward object, which since it has become asubject for the discipline has obliged anthropologists to re-examine their disciplinary identity and re-think their theoretical bases. We start from the idea that both the emergence and the decline of peasant studies in the discipline have corresponded with localizable social, intellectual and political contexts. For this reason we present the current struggle of peasant internationalism, represented by the international movement Vía Campesina, for food sovereignty and international recognition of the rights of peasant men and women. These struggles are considered to constitute a politically novel space which has the potential to generate political opportunities for peasant claims in the face of neoliberal despoliation. Finally, we reflect on how these struggles again present the peasant class as an awkward object for anthropology and demand anthropological discussion of the subject.

KEYWORDS Peasant class, anthropology, agrarian issue, social movement, Vía Campesina, food sovereignty, human rights.

Evaluation of the peasant concept in anthropology -its inception, growth, and demise - is inseparable from an evaluation of the broader intellectual context of social anthropology in which it is found.

Michael Kearney

La historia de los estudios campesinos tendrá que escribirse alguna vez... Espero que cuando se escriba esta historia sea realmente un reflejo de la historia del campesinado. Es decir, no una simple historia de una rama especial de las ciencias sociales, sino una parte de la historia social de los campesinos. Ángel Palerm 


\section{Introducción}

En la actualidad, en términos absolutos, existen más campesinos que nunca antes en la historia de la humanidad. Pese a ello, en la globalización neoliberal, su existencia no es una realidad evidente ni para el pensamiento social ni para las ciencias sociales, que se debaten entre el silencio y la negación respecto del campesinado. Existe lo que Van der Ploeg define como invisibilidad fabricada que se combina con la omnipresencia del campesinado en el mundo (Ploeg, 20I0). Algo cercano a lo que Lacan definió como forclusión, para señalar el operativo de expulsión simbólica de algo que existe y retornará constantemente en lo real (Bidaseca, 2006).

En este artículo elaboro una discusión inicial respecto de la persistencia del campesinado en la antropología como objeto incómodo, que desde su irrupción en la disciplina ha obligado a ésta a rediscutir su identidad disciplinaria y a repensar su cuerpo teórico. Se parte de la idea, como señala el epígrafe de Kearney, que tanto la emergencia como el ocaso de los estudios campesinos en la disciplina se corresponden con contextos sociales, intelectuales y políticos localizables. Por ello es que presento la actual lucha del internacionalismo campesino, liderado por el movimiento transnacional Vía Campesina, en torno a la soberanía alimentaria y el reconocimiento internacional de los derechos de los campesinos y campesinas. Estas luchas constituyen un espacio políticamente novedoso y potencialmente generador de oportunidades políticas para las reivindicaciones campesinas frente al despojo neoliberal, a la vez que vuelven a presentar al campesinado como un objeto incómodo para la antropología y, con ello, a reclamar la reflexión disciplinaria.

El artículo contiene siete apartados. En los tres primeros, guiado por el epígrafe de Palerm, presento un esbozo de la historia del campesinado en la antropología, la emergencia de la categoría antropológica de campesinado, su devenir en el contexto del desarrollismo y su ocaso en tiempos del globalismo neoliberal. A continuación, desarrollo una discusión en torno al tratamiento de la cuestión agraria y su rediscusión en el marco de la globalización, a fin de introducir algunos elementos contextuales que definen la emergencia del internacionalismo campesino. En los apartados cuarto y quinto presento dos de las principales luchas contemporáneas del movimiento campesino transnacional: la soberanía alimentaria y la declaración internacional de derechos campesinos. Por último, en los apartados finales propongo una reflexión en torno a los desafíos que el internacionalismo campesino, especialmente en lo 
relativo a las luchas por sus derechos, presenta a la antropología y los estudios campesinos.

\section{El objeto incómodo}

En 1972 Teodor Shanin caracterizó al campesinado como la clase incómoda. Aquella clase que contradecía los planes y profecías, las ordenadas tendencias y modelos ideales que definían el mundo pensado y estructurado como una cadena de transferencia fordista hacia el futuro, donde todo debía funcionar a tiempo y sin interrumpir el proceso. Parecía ser que en ese modelo teleológico los campesinos persistían en la anomia y ganaban su lugar en la cadena justamente contradiciendo su curso.

Quizá para ninguna otra ciencia social la emergencia del campesinado y su persistencia ha sido más incómoda que para la antropología. Acomodada en una división del trabajo científico que la insertó en las periferias de la periferia, prematuramente tomó distancia de la problemática de pensar las transformaciones globales que desde los centros irradiaban hacia los contextos de observación etnográficos. Así, desde su fundación como ciencia, la antropología encontró escollos para definir a los que no eran ni salvajes, ni civilizados, ni primitivos, ni modernos, ni cultura, ni totalmente clase, ni otros, ni totalmente nosotros. Resultaba que ese inmenso sector social, que luego se denominó campesinado, no vivía en aldeas, sino en países o continentes completos y que su comportamiento -en especial el político- pese a tener una firme conexión con el pasado, era el vehículo de entrada de esos países y continentes a la historia moderna, a la escena mundial. Más problemático aún, en muchos casos su entrada al plató de la historia se hacía rompiendo la escena en la que la antropología se había especializado como la mejor guionista: el colonialismo.

El arribo del campesinado representó un dilema para la teoría antropológica construida sobre la base de categorías polares. Su inclusión en el quehacer disciplinario fue clave para que la antropología se integrase a la discusión sobre la expansión de las relaciones capitalistas y la acción colectiva de los sujetos subalternos frente a ella. En este marco, la irrupción de «la ambigua categoría de campesino desafiaba al dualismo puro de la antropología clásica, constituía una incomodidad intelectual o cognoscitiva para la disciplina, además de representar una categoría política potencialmente perturbadora a escala mundial» (Kearney, I996: 36).

El interés por el estudio de las sociedades campesinas y la introducción de 
una categoría para definirlas en el marco de la teoría antropológica, se vinculó con el proceso de expansión de las relaciones capitalistas, con la progresiva desaparición de los pueblos indígenas en el contexto post Segunda Guerra Mundial y con el «ingreso de las principales naciones mayoritariamente campesinas de Asia, Medio Oriente y América Latina al escenario de la política internacional» (Geertz, I96I: I). En un contexto de lucha por la emancipación de los pueblos coloniales o semicoloniales, la atención de los estudiosos en los países subdesarrollados se desvió desde los grupos tribales o primitivos, hacia las poblaciones rurales campesinas (Stavenhagen, I969).

La irrupción del campesinado en la antropología fue el detonante para que ésta tuviese que pensar horizontes más allá del plácido vientre de la no historia, entrando en la discusión de un mundo que cambiaba condicionado por tendencias que difícilmente podían ser captadas únicamente desde el «estar ahí» malinowskiano. El "otro absoluto», distante temporal y espacialmente, construido por la etnografía clásica, debía replantearse en un "otro relativo» (Owen, 2005) y contemporáneo, cuya historia no podía entenderse sino dentro de la propia historia del capitalismo y cuyo presente estaba cruzado por las dinámicas de ampliación capitalista.

Por medio de la investigación de las sociedades campesinas la disciplina ingresó al estudio de las sociedades complejas. La condición de otro relativo y contemporáneo del campesinado, inserto en sociedades mayores y condicionado por las dinámicas sociales, económicas, políticas y culturales de éstas, estuvo presente desde las primeras definiciones teóricas del campesinado que hicieran Robert Redfield en I94I, Raymond Firth en I944 y Alfred Kroeber en 1948, definiciones que encontraron mayor elaboración teórica con Eric Wolf en 1955 .

Si el agente de cambio social en la etapa fundacional de la disciplina fue el colonialismo, para el periodo en que surgen y se consolidan los estudios campesinos lo fue la modernización y el desarrollo. La narrativa del desarrollo, inaugurada el 1949 con el discurso de investidura del Presidente de Estados Unidos Harry Truman, creó una nueva forma de pensar y mirar a las sociedades antes primitivas y lejanas. El bloque subdesarrollado del mundo constituía la mayoría del planeta y el bloque restante, el desarrollado, asumía la tarea histórica de acompañar el cambio social planificado por medio de un desplazamiento de estrategia civilizatoria para la ampliación del capitalismo, que pasaría del antiguo imperialismo colonial a un «régimen de cooperación».

No se necesitó densa evidencia etnográfica para concluir que las tres cuar- 
tas partes del mundo, el amplio sector subdesarrollado, estaba habitado por personas que vivían de prácticas productivas preindustriales. Lo necesario fue equiparar dichas prácticas extremadamente diversas, a fin de insertarlas en un mismo proyecto de cambio que les asegurara su entrada a la modernidad capitalista. El tropo que, a modo de sinécdoque, podía contener toda esa diversidad, lo encontraron primero la política y luego las ciencias sociales en el campesinado, que se insertó como categoría intermedia entre lo primitivo = subdesarrollado y lo civilizado $=$ desarrollado. ${ }^{2}$

El campesinado, que había sido la antítesis del primer proyecto modernizador y refugio para los que pensaron modernidades alternativas desde lo tradicional, como el romanticismo alemán o el narondnismo ruso, pasó a ser un sector social y una categoría central en el discurso y en las políticas de desarrollo. Como ha señalado Escobar (2007: 265-66), la inclusión del campesinado en el aparato del desarrollo fue el primer caso en que se creó masivamente «un nuevo grupo de clientes para dicho aparato, en el cual la visión economicista y tecnologizante se orientó hacia un nuevo sujeto» y hacia la transformación de las condiciones de vida para convertirlas en un «ambiente social normalizado y productivo».

A partir de los trabajos de comunidad de Robert Redfield, gran parte de las etnografías sobre las comunidades rurales y el campesinado se centraron en su comportamiento económico, relacionado con sus actitudes, valores, tradiciones y sistemas cognoscitivos, enmarcados en el argumento de la especificidad cultural de este sector (Heynig, I982) y la incidencia de ésta en el éxito o fracaso de las políticas de modernización. Las tipologías folk y urbano de Redfield fueron tempranamente traducidas por el discurso de la modernización y posteriormente del desarrollo, en las tipologías tradicional y moderno, ambas entendidas como polos que debían y podían integrarse por medio de la acción política y técnica, que disolviera la primera en la segunda. La trascendencia que en este ámbito tuvo la antropología redfieldiana se manifiesta en que, junto a la sociología weberiana-parsoniana y la economía neoclásica, integró los tres pilares sobre los cuales se construyó la teoría de la modernización (Kearney, I996: 50).

Tanto la popularización de la propuesta de Redfield, como las críticas que recibió, encontraron como contraparte empírica la primera revolución decididamente reconocida como campesina, la Revolución China de I950. Si bien

2. Véase en Kearney (1996: 36) la figura 2.I: Classical and modern Anthropology. 
el impacto de este proceso revolucionario en la academia fue tardío, en el gobierno norteamericano encendió tempranamente la alerta sobre el curso de la política de modernización y desarrollo que, como hegemonía expansiva para contención del comunismo, se había puesto en marcha desde el gobierno de Truman. Esta alerta se agudizó con el triunfo de la guerrilla cubana en I959 y, unos años más tarde, por el vuelco al marxismo del gobierno revolucionario de la isla.

«No podemos dejar de exportar ejemplo», había dicho Ernesto Guevara en I96I. Para bloquear dicha exportación simbólica se implementó un profundo plan de ayuda al desarrollo que, en paralelo a la política contrainsurgente, debía permitir el despegue económico del Tercer Mundo formulado en I960 por W.W. Rostow en Las etapas del crecimiento económico. ${ }^{3}$ Rostow, que desde entonces se transformó en uno de los intelectuales orgánicos más influyentes para el desarrollismo, había señalado que el primer paso hacia el despegue económico era romper la inercia de las sociedades tradicionales.

La especialización de la antropología en las sociedades tradicionales le permitió ganar un espacio privilegiado en las discusiones del desarrollo ya que, para la narrativa desarrollista, tradición y pobreza eran pares indisociables. Como apuntó, Mintz, «la gente más pobre de las sociedades menos desarrolladas es, en muchos aspectos, la más tradicional» (Mintz, I996: I9), y para los desarrollistas

la cultura de las sociedades tradicionales fue percibida como el obstáculo fundamental para su desarrollo, en la medida en que dichas culturas eran identificadas con actitudes de fatalismo, inmovilismo y oscurantismo y con estructuras sociales obsoletas. Por lo tanto, la única vía hacia el desarrollo pasaba por la adopción del «paquete cultural occidental» al completo: capitalismo, industrialización, tecnología avanzada, y democracia representativa, pero también individualismo, secularización y utilitarismo (Viola, 2000: I6).

3. El libro se publicó en inglés en I960 bajo el título The Stages of Economic Growth: A Non-Communist Manifesto (Las etapas del desarrollo económico: Un manifiesto no comunista), y fue traducido al año siguiente por el Fondo de Cultura Económica, ejerciendo gran influencia sobre las ciencias sociales de América Latina y sobre los gobiernos y expertos económicos de la región (Borón, 2008: 2I). 
La cultura tradicional, campesina, debía modernizarse, por medio de la monetarización de las relaciones económicas, la urbanización de su población y la industrialización de la producción. El sector industrial debía controlar la producción agraria, sus procesos y su reproducción. La producción del campo dejaría de cumplir la función tradicional de reproducción de poblaciones y prácticas socioculturales tradicionales, para pasar a ser insumo del proceso industrial, en términos de materias primas, alimentos y mano de obra.

Muchos antropólogos llevaron a cabo sus estudios de las sociedades rurales en el marco de los programas para el desarrollo, en un periodo en que, como señaló Pérez-Vitoria (20I0), a los campesinos nadie quería entenderles, todo el mundo estaba demasiado ocupado en modernizarles. La parte de la disciplina más implicada en la ofensiva modernizadora consideró que el antropólogo podía jugar un rol crucial como catalizador de procesos de cambio social, mediante el despliegue de estrategias como la «aculturación dirigida» o planificada (Viola, 2000: 24).

Lo anterior parecía ser una cuestión reñida con la identidad disciplinaria de la antropología, edificada sobre las ideas de la diversidad cultural y el particularismo. ¿Cómo podía la antropología resolver coherentemente la tarea de hacer que los campesinos, para sobrevivir en el capitalismo, dejaran de ser campesinos? El consenso -más allá de las discrepancias teóricas- se expresaba en la praxis antropológica al servicio del cambio que, mientras para algunos era un fin pragmático y necesario, para otros significaba una cuestión teóricamente inevitable en el curso de la historia hacia la desaparición del campesinado. ${ }^{4}$

Frente a la ineficacia o al incumplimiento del cambio, muchos antropólogos recurrieron a definiciones cercanas a la cultura y la personalidad, la psicología social, los ethos y otras cuestiones que confirmaban el imaginario social de la modernidad en contraposición a lo tradicional y los tradicionales, su apatía al cambio, su desconfianza, su individualismo y su constante sospecha de lo exógeno, que en elucubraciones más elaboradas resultarían en lo que George

4. El modernismo como pensamiento de época inundó los abordajes de las ciencias sociales en general y de la antropología en particular, y para sus más acérrimos defensores la existencia del campesinado y su racionalidad constituía un estorbo al desarrollo que retrasaba el proceso de acumulación de capital y el despliegue completo de los mercados (Ploeg, 20I0). La impronta modernista se expresó en las opciones capitalistas y socialistas; para esta última la «eliminación del campesinado [...] (era) una cosa buena, aunque dolorosa» (Bernstein, 20I2: I2I). 
Foster denominó la orientación cognoscitiva para explicar el comportamiento campesino, centrado en la imagen del bien limitado que inclinaba al campesinado a no perturbar el equilibrio social en el marco de una economía no productiva.

Esta imagen, junto a las que se crearon desde los estudios de comunidad, fortalecieron las definiciones acerca del dualismo económico sobre las que se orientaron las políticas de modernización en las décadas de despliegue intensivo de la Revolución Verde, tendientes a acabar con la economía campesina tradicional e incrementar la productividad agrícola mediante la inversión y la asistencia técnica, traducidas en la transferencia de capital y tecnologías.

Los agitados años setenta marcaron importantes puntos de inflexión en términos del estudio antropológico del campesinado. Contradictoriamente, en la misma década en que la hegemonía del discurso desarrollista comienza a desvanecerse o a transformarse hacia lo que posteriormente será el neoliberalismo, en la disciplina se institucionalizó el subcampo de la antropología y el desarrollo. En estos años, además, cuajaron diversas tendencias que condujeron a una renovación de la antropología y que, entre otras, indican el surgimiento de la antropología marxista.

Si el estructural-funcionalismo fue la referencia teórica central de la antropología política y económica clásica, la referencia más importante de los estudios en esos campos desde los setenta, especialmente en la academia norteamericana, fue el marxismo; no necesariamente porque la mayoría de las etnografías del periodo sean de cuño marxistas, sino porque el marxismo fue referencia general, tanto para los que lo adoptaron de manera directa o indirecta, como para los que lo criticaban o rechazaban (Comas, I998; Caldeira, I989).

La influencia que en la disciplina comenzaron a adquirir la teoría de la dependencia y la teoría de sistema mundo posicionó el debate sobre la situación de los países tercermundistas en el marco de las relaciones históricamente desiguales que posibilitaron la emergencia global de un polo desarrollado y otro subdesarrollado. Con ello se comenzó a desestimar el valor explicativo de las teorías de la modernización, el dualismo, el carácter unilineal del desarrollo y la supuesta ecuanimidad entre crecimiento económico, racionalidad y progreso. Estas críticas cristalizaron en la emergencia de la economía política, perspectiva en la cual el campesinado, la sociedad rural, el movimiento campesino y la cuestión agraria, en general, tienen un lugar preponderante. ${ }^{5}$

5. Por la influencia de la economía política, los estudios campesinos tuvieron una 
Pero, más allá de los giros teóricos en la disciplina, la importancia que comienzan a adquirir los estudios campesinos en esta época se debe ante todo, como observó Palerm (2008), a los campesinos mismos; a sus luchas y resistencias, a su porfiada forma de negar el curso «natural» de la historia. Estas luchas inclinaron a que parte de los antropólogos marxistas (teóricos y militantes) vieran al campesinado como una clase o un sector de clase, sino de vanguardia — por lo menos-, imprescindible para pensar la revolución.

Entre la década de los setenta y la primera parte de los ochenta, las críticas frente a los fracasos de las políticas de desarrollo y modernización, junto a la influencia de la opción revolucionaria que, desde la experiencia cubana, se fue anidando como alternativa para la liberación política y económica de los pueblos del entonces Tercer Mundo, abrió espacio para un renovado espíritu campesinista en la teoría antropológica, que pese a retomar elementos centrales del marxismo, discutía el carácter teleológico del destino del campesinado en el desarrollo del capitalismo. El estudio del potencial revolucionario del campesinado, de las capacidades de alianza entre éste y los sectores proletarios y subalternos urbanos, la articulación de modos de producción, las etnografías de la resistencia y la economía moral, entre otras discusiones, ocuparon un lugar preponderante en la producción disciplinaria de este periodo.

Pero las conocidas derrotas de los proyectos anticapitalistas que articularon las luchas de los trabajadores y las clases subalternas en la etapa anterior posibilitaron que se llegue a los años ochenta con un movimiento popular desfavorecido, desarticulado, altamente reprimido y sin la referencia de los socialismos reales, que mostraban también sus debacles. Es dicha derrota histórica la que explica el carácter de la reestructuración productiva, la esencia excluyente del nuevo régimen de acumulación neoliberal y su consustancial internacionalización del capital en un régimen de acumulación flexible: la globalización. Ésta, junto a socavar la soberanía de los Estados nacionales (en especial de los más pobres), posibilita la explotación del trabajo con base en la exclusión de los productores locales (Rubio, 20I2).

preponderante presencia en la producción académica de los años setenta, a la par del gran auge del marxismo en la discusión disciplinaria. La creación en 1973 del Journal of Peasant Studies y la constante participación de antropólogos, interesados en el campesinado y la ruralidad, en las revistas de orientación marxista Critique of Anthropology y Dialectical Anthropology, creadas entre 1974 y I975, son expresión de la importante presencia de la temática en el debate antropológico. 
En el plano de la teoría social, la derrota señalada se expresó en el colapso de la teoría crítica moderna y la instalación del posmodernismo como tendencia dominante en ciencias sociales (Santos, 2007) y, muy especialmente, en antropología. Con el posmodernismo la revisión con afán deconstructivo de los conceptos, categorías y tipologías fundantes de las disciplinas se hizo una constante, centrada en la crítica a la idea de totalidad que les sustentaba. Así, dichas categorías perdieron vitalidad en la discusión teórica, siendo "desenmascaradas» como meras construcciones discursivas, acusadas de ser nieblas que aletargaban la vivacidad del flujo de los acontecimientos, los fragmentos y la diversidad. En este ambiente intelectivo, la categoría antropológica de campesinado, cuando no abandonada de plano, fue rediscutida junto a los conceptos que acompañaron sus definiciones, especialmente el de clase social.

La instalación hegemónica del globalismo neoliberal desfiguró la presencia del campesinado en el ámbito económico simultáneamente a que le desmantelaba como sujeto político. Al mismo tiempo, los campesinos iban desapareciendo de los itinerarios de investigación de la antropología y de otras ciencias. Como escribió Blanca Rubio:

Ningún sector ha resentido la marginalidad en todas sus dimensiones como los campesinos [...] despojados de su razón de ser y de existir en el capitalismo neoliberal: perdieron su condición de productores y receptores de políticas públicas, el reconocimiento social y hasta su identidad y pertinencia como objeto de estudio de las ciencias sociales (Rubio, 2006: 2).

Los arduos debates campesinistas-descampesinistas o los elaborados argumentos sobre el potencial político del campesinado, las vías de desarrollo del capitalismo en el agro, la articulación de modos de producción, la autonomía y el control del proceso productivo, dieron paso al silencio o a la búsqueda por dotar de identidades poscampesinas, afines a las teorías posmodernas y a la de los nuevos movimientos sociales, a aquellos sujetos que desde los campos del mundo resistían, desde la última década del siglo XX, a las políticas neoliberales.

En las postrimerías del siglo XX y con la globalización neoliberal como principal fenómeno, la incomodidad del «objeto» campesino parecía resolverse negando la dimensión de clase de sus luchas y esencializando las identidades desde las que se articulaban sus discursos. Mediante este mecanismo se alzaba a la cultura y la identidad como los factores centrales en la reproducción y la 
resistencia de los sectores excluidos por el modelo. El resultado de esto fue doble: por una parte desaparecían del debate antropológico los sectores del campesinado que insistían en la lucha por la tierra, la producción o los precios y, por otro, se alzaban las particularidades étnicas como elemento que, a la vez que negaba las características materiales de las luchas, excluía a los sectores mestizos del campo, los que al no ser indígenas parecían carecer de cultura y, por tanto, de potencial para resistir al modelo y ser de interés para el estudio de la antropología.

\section{La cuestión agraria y la globalización}

El debate de la cuestión agraria clásica se centró en las problemáticas de la producción, la acumulación y la diferenciación de clase, en el marco del desarrollo del capitalismo y la consolidación de la producción industrial como vanguardia del mismo, dentro del cual el destino del campesinado era ineluctablemente - aunque con matices en la velocidad del proceso- la transformación en proletariado rural o urbano, los más, y en burguesía agraria, los menos. Desde el punto de vista político, el estudio de las sociedades rurales buscaba avizorar los comportamientos de las fracciones de clase rurales en los procesos revolucionarios y de transición al socialismo, así como también visualizar alternativas para el cambio estructural en los países de desarrollo deficiente.

Algunos bemoles a los tópicos señalados, aportados por teóricos marxistas tardíamente recuperados en la discusión sobre la cuestión agraria, proporcionaron elementos para sostener tesis sobre la no linealidad del desarrollo capitalista en el agro, el desarrollo desigual y combinado del capitalismo en espacios de desarrollo deficiente, la articulación de modos de producción, el potencial revolucionario del campesinado y las lógicas de reproducción de las unidades campesinas, así como la continuidad de procesos de acumulación primitiva que constreñían al capitalismo a crear y recrear a los sectores pre o no capitalistas del campo.

El proteccionismo agrario, instalado en la mayoría de los países del mundo después de la Gran Depresión de los años treinta del siglo XX y consolidado en el periodo de posguerra - bajo las tesis del keynesianismo y del desarrollo nacional industrial—, inclinó a definir las tendencias en torno a los niveles de desarrollo del capitalismo agrario como una cuestión circunscrita a las economías nacionales y a las políticas adoptadas por los Estados. De este modo, un problema central de la discusión sobre la cuestión agraria post Segunda 
Guerra Mundial fue que se planteó en los marcos teóricos del análisis marxista precedente, sin necesariamente atender al cambio de contexto y a los objetivos sobre los cuales originalmente se proyectó. La preocupación del siglo XIX estribó en la transición al socialismo y el lugar que en éste debían ocupar las economías agrarias, por lo que correspondió a un debate eminentemente político. Mientras tanto, en el periodo de posguerra el debate fue entendido en el marco del desarrollismo y de las limitantes que la persistencia del atraso campesino ejercía sobre el pleno desarrollo del capitalismo nacional (Araghi, 2009).

La unidad de análisis de la cuestión agraria clásica, tanto en las reflexiones sobre la acumulación primitiva, como en el desarrollismo nacional de posguerra, fue el Estado-nación. En el contexto de las economías protegidas de posguerra, los caminos del desarrollo capitalista en la agricultura en cada uno de los países se suscribían al desarrollo de la industria nacional (Bernstein, 20I4), de ahí que la reflexión se centrase en las consecuencias políticas de la subordinación de la propiedad agraria al capital, en el contexto de una importancia decreciente de la sociedad rural al interior de las fronteras nacionales.

La centralidad del desarrollo industrial nacional y su consecuente capitalismo agrario, resultó en que, durante el periodo señalado, la dimensión global de la cuestión agraria quedase subsumida en las dinámicas nacionales que, a la vez que fracasaban en el intento de hacer coincidir teoría e historia, proyectaban como elementos finalistas las tendencias observadas en la ampliación del capitalismo en los espacios rurales nacionales (descampesinización/ campesinización). ${ }^{6}$ El asunto era que mientras se entendía la economía y sus tendencias diferenciadoras al interior de los países como determinadas por las fuerzas políticas nacionales y la intervención de los Estados, se descuidaba el

6. Según Araghi (2009), dichos elementos formaban parte de un enfoque determinista y teleológico en el que se podían reconocer tanto a los teóricos de la cuestión campesina en su entendimiento marxista ortodoxo, como a aquellos que defendían —bajo el paraguas chayanovista- la permanencia per secula seculorum del campesinado. El autor señala que, durante más de un siglo, los debates sobre la "cuestión campesina» fueron dominados por dos grupos: por un lado los que, con Lenin y Kaustky, defendían la tesis de que la inevitable expansión del capitalismo conducía al exterminio de los campesinos y, por otro lado, los defensores de la tesis de la persistencia que, con Chayanov, argumentaban que el modo campesino de producción posee lógicas diferentes a las del capitalismo que le permiten reproducirse más allá de las presiones de éste sobre la economía familiar campesina. 
análisis de la esfera económica global del desarrollo capitalista que marcaba las pautas de la cuestión agraria a nivel mundial. De ahí que muchas de las bases argumentativas de la cuestión agraria clásica perdieran atingencia con la eclosión de la globalización neoliberal.

El fin del Bretton Woods y la instalación del Consenso de Washington implicaron, especialmente en los países del Sur, la reducción del control político nacional sobre las tendencias que orientaban el desarrollo. En I985, con la inclusión del comercio de alimentos en la disciplina del $\mathrm{GATT}^{7}$ se dejó atrás la era del proteccionismo agrario y se posibilitó la instalación hegemónica de potencias agroalimentarias, especialmente las provenientes de los países ricos, que coparon el mercado y propiciaron el desmantelamiento de la mayoría de los productores de los países pobres que, imposibilitados de competir en condiciones tecnológicas, económicas e institucionales desfavorables, no pudieron integrarse al mercado globalizado, ni mantener su funcionalidad en las economías nacionales.

El rol del mercado global en la radical transformación de la realidad agrícola mundial desde las últimas décadas del siglo XX marcó, según algunos autores (cf. Bernstein, 20I I), el fin de la cuestión agraria, su resolución global en los términos en que fue teorizada clásicamente, vale decir, como la cuestión agraria del capital, del desarrollo de éste en el campo o de su control sobre la agricultura. En este sentido se afirma que no ha sido necesario el desarrollo del capitalismo agrario en las naciones del hemisferio sur, para que el mercado global de alimentos funcione. El capitalismo globalizado ha logrado orientar los desarrollos desiguales del agro a un funcionamiento en que cada espacio se ve compelido a integrarse a las dinámicas globales. Esta lógica de subsunción explica el control del capital sobre el trabajo y la producción agrícola internacional, más allá de los niveles de desarrollo formal del capitalismo agrario dentro de las fronteras nacionales.

En el contexto del dominio neoliberal, la pregunta que orientó el estudio de la cuestión agraria clásica de Kautsky, en torno a observar si, y de qué manera, está el capital tomándose la agricultura, revolucionando, haciendo las viejas formas de producción y propiedad insostenible y creando nuevas necesidades (Kautsky, 2005 [I 899]), pareciera estar resuelta, por lo menos en la primera parte de su formulación. En concordancia con el párrafo anterior, el dominio

7. General Agreement on Tariffs and Trade (Acuerdo General sobre Aranceles Aduaneros y Comercio) antecesor de la Organización Mundial de Comercio (OMC). 
del capital sobre la producción agrícola es un fenómeno global, incluso en aquellos espacios donde por estrategia cultural o económica defensiva la producción campesina se destina al autoconsumo.

No obstante, dos interrogantes parecieran continuar pendientes: I) ¿de qué manera se expresa el dominio del capital sobre la agricultura en esta fase de acumulación?, y 2) ¿cómo dicho dominio se profundiza y/o resiste? Con dichas interrogantes pendientes es difícil sostener el argumento en torno al fin de la cuestión agraria. Como han hecho trabajos recientes (Akram-Lodhi y Kay, 20I0; Fairbairn y otros, 20I4; Bernstein, 20I2; Moyo, Jha y Yeros , 20I3), el punto está en caracterizar las nuevas formas en que se expresa la cuestión agraria contemporánea en el marco del dominio neoliberal y sus mutaciones en contexto de crisis.

La globalización neoliberal y la constelación de crisis (económica, medioambiental, alimentaria y energética) que acompaña al capitalismo desde los albores del presente siglo, así como los argumentos políticos y económicos que se disputan la hegemonía para salir de las mismas, han implicado la eclosión de una serie de nuevos fenómenos asociados al campo, la agricultura y la ruralidad. Estas circunstancias, como plantean Akram-Lodhi y Kay (20I0), hacen pensar que es un mal momento para dudar de la relevancia que continúa teniendo la cuestión agraria. Al mismo tiempo, la pertinaz resistencia de los movimientos campesinos en todo el globo permite sostener que la vigencia de la cuestión agraria, como expresión particular de la lucha de clase, es un capítulo sobre el cual el capitalismo y sus escribanos no han podido siquiera bosquejar un colofón.

\section{Del movimiento campesino nacional al internacionalismo campesino}

Durante gran parte del siglo XX los movimientos campesinos fueron fundamentales para entender las dinámicas políticas de la mayoría de los países del globo. Las luchas campesinas permitieron a varias naciones ingresar a la «modernidad»y, a otras cuantas, posicionarse de forma activa en el cuadro geopolítico que definió el siglo pasado. Bajo la bandera de la liberación nacional, la lucha revolucionaria o la reforma agraria, los movimientos campesinos se organizaban y disputaban dentro de los marcos de las colonias o de los Estados nacionales, aun cuando en ellos podían observarse diversas influencias políticas e ideológicas internacionales.

Pese a la diversidad de expresiones del movimiento rural del siglo XX, la 
lucha por la tierra fue la principal demanda de los campesinos organizados. La temprana observación de que dicha lucha sectorial y eminentemente económica podía derivar en conflictos políticos de proporciones capaces de transformar toda la estructura de la sociedad, especialmente en aquellos países de importante población campesina, derivó en la definición de una política internacional tendiente a frenar dichos procesos.

Siguiendo a Armando Bartra (2006), el hecho de que el campesinado fuera una clase constituyente del capitalismo, en las condiciones de transición truncada de los países del Sur, es decir, en el contexto de la incapacidad estructural del capital para lograr la proletarización plena de los despojados del campo, llevaba a los productores rurales a luchar contra su descampesinización y a reivindicar la lucha por la tierra que, en ciertas circunstancias, podía constituir una lucha revolucionaria que cuestionaba el dominio de los medios de producción por la burguesía.

La lucha por la tierra y la reforma agraria se transformó en bandera nacional de los movimientos campesinos, siendo un episodio crucial de la formación política de la clase campesina en cada uno de los países donde se desarrollaron estos procesos. Es posible apuntar que en las luchas nacionales por la tierra, el campesinado se fue descubriendo como clase, colocó e interpretó sus intereses a nivel estructural, visualizó a sus enemigos inmediatos y a su enemigo principal, estableció alianzas, negoció, midió su potencial y trazó proyectos políticos. Esto puede verse sintetizado en el lema de la Coordinadora Nacional Plan de Ayala, uno de los principales movimientos campesinos independientes de México en la segunda mitad del siglo pasado, que expresaba: «Hoy luchamos por la tierra y también por el poder».

Las políticas de desarrollo que implicaban la integración del campesinado al modelo de producción nacional, funcionalizando la producción local como abastecedora de alimentos y materias primas baratas, abrió una amplia ventana de oportunidad política para la acción colectiva por la tierra y la reforma agraria. Empero, la experiencia de varios países de América Latina ejemplificaba que las características que adoptaban las reformas agrarias se debía sobre todo a la participación de los campesinos en el proceso y no constituían dádivas de un capitalismo de rostro amable que buscaba modernizarles, sino que se correspondían con las luchas campesinas, con su capacidad o incapacidad para hacer frente a las transformaciones estructurales y a las contradicciones de un modelo de desarrollo nacional sostenido sobre la base de la explotación del campesinado.

Las transformaciones de la cuestión agraria en las décadas finales del siglo 
XX, discutidas en la sección anterior, clausuraron la oportunidad política para la lucha por la tierra. La reforma agraria dejó de ser interés de los Estados y el campesinado fue desvinculado del modelo de producción. La apertura de los mercados agrarios y el control de éste por los países centrales, invirtió el panorama de los países excedentarios y deficitarios de alimentos (especialmente de granos básicos) para lo cual fue necesario desactivar la producción local y excluir de su rol de productores a los campesinos del Sur. Colmando con alimentos exportados el mercado interno de los países pobres, se ratificaba la redundancia económica de los campesinos y se les condenaba a la quiebra, al no poder competir con los productores altamente subsidiados de países ricos y con agroempresas transnacionales altamente capitalizadas.

Los Estados implementaron profundas políticas de contrarreforma agraria, ligados a programas de ajustes estructurales diseñados por organismos internacionales como la OMC, el Banco Mundial y el Fondo Monetario, que derivaron en la reconcentración de la propiedad de la tierra con participación cada vez mayor de capitales extranjeros, especialmente dedicados al monocultivo de exportación.

Con salvadas excepciones, como la del Movimiento de los Trabajadores Rurales Sin Tierra de Brasil, los movimientos campesinos nacionales sufrieron un importante reflujo durante toda la década final del siglo pasado. Sin embargo, esa misma década coincidió con la eclosión del movimiento campesino internacional ligado al movimiento altermundista.

El levantamiento del Ejército Zapatista de Liberación Nacional (EZLN) en 1994 en Chiapas, México, constituye un antecedente fundamental de esta eclosión. Desde sus primeras declaraciones, los zapatistas vincularon el discurso agrarista con uno de carácter etnicista, contenido en una reflexión que ponía a la globalización neoliberal en el centro de la discusión. Su oposición a la apertura comercial de México por medio del TLCAN y la clausura de la política agraria en el país, la engarzaban a la crítica al modelo global que se imponía con la nueva fase de acumulación capitalista. Estas ideas se consolidaron en el Primer Encuentro Intercontinental por la Humanidad y Contra el Neoliberalismo de 1996, realizado por iniciativa del EZLN en Chiapas. Este encuentro marcó el inicio de las articulaciones globales de movimientos altermundistas.

Pese a que el Estado, aun en el contexto de la globalización, continúa siendo la esfera crítica para la imposición de los intereses de las clases dominantes, el reconocimiento de la dinámica mundial dirigida por el interés de corporaciones e instituciones supranacionales, ha sido un imperativo para que la orga- 
nización de los campesinos se constituya en un sujeto político transnacional, que brega en la arena de la gobernanza global por los intereses de los pequeños productores rurales del mundo. La expresión concreta de esta organización transnacional es la Vía Campesina.

La articulación internacional del movimiento campesino es reciente en la historia de los movimientos sociales, si se le compara con la dilatada historia de organizaciones obreras internacionales. Si bien, desde 1946 existe la Federación Internacional de Productores Agrícolas, ésta es integrada principalmente por medianos y grandes agricultores, mayoritariamente pertenecientes a países desarrollados, por lo que su política ha tendido a estar dominada por los intereses de este sector que, en su mayoría, se ha visto beneficiado de las neorregulaciones globales en agricultura.

Las vinculaciones internacionales del movimiento campesino pueden rastrearse en la década de los setenta. Tras la crisis alimentaria global de I974, las organizaciones campesinas comenzaron a presionar a nivel internacional a fin de que se interviniese a favor de la soberanía alimentaria (Rodríguez, 20I0). De esas primeras luchas y de la preocupación de muchos países ante la crisis, surgió la Conferencia Mundial sobre Reforma Agraria y Desarrollo Rural, auspiciada por la FAO, de la cual resultó la «Carta del Campesino», programa tendiente a promover un paquete de medidas para la participación política, la producción y el desarrollo del campesinado como sostén de la seguridad alimentaria. Este programa fue prematuramente abandonado en pro de las políticas neoliberales.

Es precisamente en el contexto de la instalación del neoliberalismo a nivel global en donde se establecen las bases para la formación de la Vía Campesina. A finales de I980 y principios de I990, «en Europa, América del Norte y Centroamérica, el avance de la economía de integración regional condujo a pequeños agricultores a formar coaliciones transfronterizas con sus homólogos de los países vecinos» (Edelman, 2005: 338 ). En ese mismo periodo, y en el marco de las negociaciones y puesta en vigor de los acuerdos de la Ronda de Uruguay del GATT, diversas organizaciones campesinas realizaron esfuerzos por unir a agrupaciones nacionales y regionales de pequeños productores rurales, a fin de hacer frente a la investida liberalizadora de los alimentos y la agricultura. De estos esfuerzos surgió, en Bélgica en I993, Vía Campesina; movimiento que en la actualidad agrupa a cerca de I 50 organizaciones de 70 países diferentes, que según se calcula representan a unos 500 millones de familias rurales en todo el mundo (Martínez y Rosset, 2013). 
Como movimiento de movimientos, Vía Campesina — desde su fundaciónadquirió un rol dual. Siguiendo a Borras (2004), esta organización aparece al mismo tiempo como actor y escenario. En tanto actor se ha constituido como movimiento transnacional en la lucha altermundista, cobrando relevancia en las movilizaciones internacionales contra la OMC y otras organizaciones reguladoras internacionales, transformándose en interlocutor válido para discutir la situación del campesinado en instancias como la FAO o la ONU. Al mismo tiempo, Vía Campesina ha devenido en un actor central entre las organizaciones y movimientos internacionales populares articulados internacionalmente.

Una de las novedades dentro del movimiento altermundista internacional es la centralidad que ha pasado a ocupar desde los primeros años del siglo XXI la Vía Campesina, como referente principal de las luchas internacionalistas. En palabras de Martínez y Rosset:

La Vía Campesina es considerada por muchos como el más importante movimiento social trasnacional en e 1 mundo [...] se ha convertido en la principal red de organizaciones de base con presencia en la antiglobalización [...] Así lo ha dejado manifiesto en sus protestas contra la Organización Mundial del Comercio (OMC) y contra el Área de Libre Comercio de las Américas (ALCA), pero también en las posturas expresadas en el Foro Social Mundial (FSM), donde ha criticado mordazmente las políticas territoriales del Banco Mundial (BM) y presionado por la adopción del concepto de soberanía alimentaria [...] Sus organizaciones miembros incluso han ayudado a derrocar los gobiernos nacionales, como en Ecuador en el 2000 y Bolivia, en 2003 (Edelman, 2005: 337); o a defenderlos, como en el caso de Honduras, en 2009 (Martínez y Rosset, 2013: 23-4).

En tanto escenario, la Vía Campesina revela toda su complejidad derivada de ser una organización profundamente diversa, que agrupa a organizaciones nacionales y regionales, con condiciones e intereses en muchos casos dispares.

Los miembros que componen Vía Campesina son extremadamente heterogéneos: desde pequeños campesinos productores de leche en Alemania a campesinos sin tierra en el Brasil; desde campesinos de granjas con excedentes agrícolas en Karnataka (India) a minifundistas en México; desde jornaleros en Nicaragua a cultivadores de arroz en Corea del Sur. El trasfondo ideológico de las organizaciones miembro es también muy 
variado: desde aquellas que proceden de marcos basados en el partido comunista a aquellas de la tradición anarcosindicalista, pasando por organizaciones con un amplio carácter liberal y las relacionadas con el activismo medioambiental (Borras, 2004: IO).

Estas organizaciones diversas que sin embargo poseen una identidad común en torno a agrupar a productores y sujetos rurales excluidos por el modelo económico global, encuentran en los foros y reuniones de Vía Campesina un escenario para la discusión de sus luchas particulares y para la formulación de agendas que, desde el plano internacional, fortalezcan las posiciones que adoptan y defienden a nivel nacional. De este escenario surgen las principales campañas que posicionan al movimiento como actor en las luchas globales altermundistas.

El internacionalismo de los campesinos se expresa en la vinculación de diversas organizaciones en un escenario común, desde el cual se constituyen en actor global. Este internacionalismo, al igual que aquel que inspiró al internacionalismo obrero del siglo XX, «identifica activamente los intereses de una clase con el interés global de toda la sociedad» (Bello, 20I 2: 30 ).

Para identificar los intereses de una clase es necesario reconocer y agrupar la diversidad de la clase, y para vincular estos intereses con los de toda la sociedad se requiere constituir un actor global que bregue por la posición de los despojados. Por estas sendas han transitado las luchas globales del campesinado en las últimas décadas. Dos de los múltiples flancos de estas luchas pueden sintetizar estos esfuerzos: la lucha por la soberanía alimentaria y la tendiente al reconocimiento de los derechos campesinos a nivel global.

\section{Vía Campesina y soberanía alimentaria}

Desde su dimensión de escenario, Vía Campesina ha reunido las diversas expresiones que defienden los pequeños y medianos productores rurales del globo en torno a la soberanía alimentaria y la función del campesinado en la concreción de ésta. Si bien la organización planteó tempranamente la discusión sobre las amenazas que las políticas liberalizadoras de la OMC representaban para la seguridad en el acceso a los alimentos y el control de los mismos por los pueblos (Desmarais, 2008), su rol como actor relevante en la discusión internacional sobre esta cuestión ha estado ligada con la crisis global de los alimentos iniciada en 2008 . La alta vulnerabilidad que se hizo patente con la 
crisis, respecto de un mercado monopolizado por megacorporaciones de países ricos, recolocó en la discusión cuestiones como la seguridad o soberanía alimentaria, la producción local de alimentos, la reactivación de las economías agrarias y la participación de la agricultura industrial-corporativa en la degradación ambiental y en la salud de las personas (Edelman, 20I4; Izcara, 20I 2).

En el marco de la crisis, lo novedoso es el reavivado interés por la discusión en torno al rol del campesinado y la agricultura familiar en la generación de un modelo alternativo, incluso entre entidades supranacionales que comandaron el cambio de foco en el desarrollo agrario desde las últimas décadas del siglo XX, tales como el Banco Mundial, el Fondo Monetario Internacional, la FAO y, en el contexto regional, la Cepal (Rubio, 20I3; Holt-Giménez y Patel, 20I2). A nivel institucional la máxima de este renovado interés fue la proclamación de 20I4 como el «Año Internacional de la Agricultura Familiar» por Naciones Unidas.

Según los organismos señalados, la seguridad alimentaria y, en un marco más general, el cumplimiento del Objetivo del Desarrollo del Milenio en torno a la reducción a la mitad de la subalimentación crónica en el mundo, requeriría el fortalecimiento de la agricultura familiar, toda vez que ésta concentra la mayor proporción de las explotaciones agrícolas del globo, es la actividad que genera más empleo en el mundo y, como subsector, es la de mayor capacidad redistributiva dentro del sector agrario que, asimismo, es el que posee mayor impacto potencial en la reducción de la pobreza en países en desarrollo, en donde la proporción mayoritaria de la población carente se concentra en las áreas rurales (FAO, Cepal e ICCA, 20I4; Banco Mundial, 2008). En este mismo tenor, en el informe de la iniciativa Evaluación Internacional del Papel del Conocimiento, la Ciencia y la Tecnología en el Desarrollo Agrícola (IAASTD, por sus siglas en inglés), promovida por Banco Mundial, ONU, FAO, y otros organismos internacionales en 2008 , se señaló:

Es insostenible depender de la agricultura industrial sustentada en la industria extractiva [...] Lograr la seguridad alimentaria y asegurar estilos de vida sostenibles para las personas que viven en pobreza crónica, requiere asegurar que los agricultores de pequeña escala tengan acceso y control de los recursos necesarios (IAASTD, 2008; citado en Holt-Giménez y Patel, 2012: 109).

El reposicionamiento de la discusión respecto de la agricultura y el ham- 
bre en el mundo, ha generado nuevos debates e importantes transformaciones en los países que desde lo legislativo debiesen derivar en políticas públicas al respecto. Ejemplo de ello son la inclusión del derecho a la alimentación y la adopción de principios de seguridad y/o soberanía alimentaria en los marcos constitucionales de diversos países. Siguiendo a Olivier de Schutter, relator especial de ONU sobre el derecho a la alimentación, el compromiso por reinvertir en la agricultura se ha tornado en una opción política central de la agenda internacional; sin embargo, esta cuestión no está cifrada en el cuánto, sino en el cómo (De Schutter, 20I0). Este señalamiento ayuda a visualizar los debates y disputas actuales respecto de las formas en que se viabilizan la producción campesina o la agricultura familiar, en las políticas agrarias y alimentarias emergentes de la crisis.

Mientras que los organismos internacionales hacen, con mayor o menor intensidad, llamados a fortalecer la agricultura familiar e integrarla a las dinámicas económicas nacionales sin cuestionar necesariamente el modelo, Vía Campesina plantea que la respuesta a la crisis del modelo mercadocéntrico de los alimentos es la promoción de la soberanía alimentaria, definida como el acceso garantizado de los pueblos a los alimentos y su «control democrático: desde la producción hasta el procesamiento, la distribución, la venta y el consumo» (Holt-Giménez y Patel, 201 2: 83).

En la propuesta de Vía Campesina, la soberanía alimentaria lleva consigo el reposicionamiento de la actividad campesina, de pequeños y medianos productores (Edelman, 20I4; Desmarais, 2008). En este sentido, la constitución de la soberanía alimentaria está inmanentemente vinculada con la recampesinización (Rosset y Martínez-Torres, 2013), es decir, con el acceso a la tierra por nuevos campesinos, así como con la transformación de las prácticas de producción, procesamiento y distribución de alimentos, en contraposición a la agricultura industrial-corporativa (Ploeg, 2010; 20I4; Pérez-Vitoria, 2010).

\section{La lucha por los derechos campesinos en el marco del neoliberalismo}

Las luchas en torno a los derechos humanos han sido un espacio fundamental para la articulación de los sectores subalternos y su constitución política en la globalización. En este periodo, la expansión del discurso de los derechos humanos en las luchas de los excluidos y explotados a nivel global, ha estado vinculado a la pérdida de referentes y la derrota política de las ideas y movimientos anticapitalistas del siglo XX. Frente a la ausencia de referentes polí- 
ticos para el cambio social radical, los derechos humanos emergieron como el medio para la canalización política popular y como uno de los espacios privilegiados en que se disputa la ciudadanía, la igualdad y la justicia social.

Desde el año 2000, Vía Campesina comenzó a plantear la necesidad del establecimiento internacional de un marco de derechos campesinos. Con ello se dio pie a una campaña tendiente a asegurar la aprobación, en la Asamblea General de Naciones Unidas, de una declaración no vinculante que, como primer paso, pueda derivar en un convenio vinculante para los Estados signatarios, supervisado por las agencias de ONU.

Pese a considerar que la lucha de los campesinos y campesinas es plenamente aplicable al conjunto de instrumentos internacionales de derechos humanos, ${ }^{8}$ y que, además, existen instrumentos internacionales que versan sobre algunas de las dimensiones reclamadas por la organización, ${ }^{9}$ las constantes violaciones a los derechos de los campesinos, el poder de las políticas neoliberales, las corporaciones transnacionales y la incapacidad $-\mathrm{O}$ en algunos casos el desinterés- de los Estados nacionales para hacerles frente, hacen necesario impulsar normas internacionales que superen las limitaciones de las existentes.

El primer proyecto de Declaración de Derechos de Campesinos fue presentado en la conferencia de Vía Campesina en 2002 en Jakarta, Indonesia. En abril de 2004 por primera vez la organización solicitó formalmente a la Comisión de Derechos Humanos de la ONU adoptar una declaración sobre derechos de «las campesinas y campesinos». En junio de 2008, el movimiento aprobó la Declaración sobre los Derechos de las Campesinas y los Campesinos y en 2009 la presentó al Consejo de Derechos Humanos. Este último, encomendó al Comité Asesor preparar un informe sobre la pertinencia de un nuevo instrumento jurídico en torno a la demanda, el que a su vez ordenó la formación de un grupo de trabajo, "Grupo de Redacción», que el 2I de febrero de 20 I 2 presentó el documento «Estudio final del Comité Asesor del Consejo de Derechos Humanos sobre la promoción de los Derechos de los Campesinos y

8. Incluyendo entre ellos a los procedimientos especiales del Consejo de Derechos Humanos relacionados con el derecho a la alimentación y a la vivienda, los derechos de las mujeres, el acceso al agua, a la salud, la protección de defensores de derechos humanos, pueblos indígenas y los relacionados con el racismo y la discriminación racial.

9. Pacto sobre Derechos Económicos, Sociales y Culturales (PIDESC), Carta del Campesino (ONU, I979), Convenio I69 de OIT, Cláusula 8-J (sobre biodiversidad), entre otros. 
de otras personas que trabajan en las zonas rurales» (A/HRC/AC/8/6), aprobado unánimemente por el Comité Consultivo de Derechos Humanos de ONU, el día 24 del mismo mes.

El 27 de septiembre de 20I2, el Consejo de Derechos Humanos de las Naciones Unidas adoptó la resolución A/HRC/2 I/L23, basado en el Estudio final del Comité Asesor del Consejo de Derechos Humanos, después de que 23 Estados miembros votaran a favor, I 5 se abstuvieran y 9 votaran en contra del texto. Esta resolución constituye un avance en torno al establecimiento de un instrumento jurídico internacional para la promoción y protección de los derechos de los y las campesinas y otras personas que habitan y trabajan en zonas rurales, población estimada en I,2 mil millones de personas. Esta es una conquista de Vía Campesina, que desde hace más de una década viene reclamando la necesidad del establecimiento de un convenio que permita a las poblaciones rurales hacer frente a la ampliación del capital y su impacto en las economías tradicionales, la biodiversidad, la soberanía alimentaria y el conocimiento biocultural.

Desde una reflexión inicial, la Resolución A/HRC/2 I/L23 podría interpretarse como la respuesta de la ONU a un grupo de interés específico de la población en su procura por alcanzar ciertas ganancias significativas en el marco de una discriminación positiva. No obstante, cabe recordar que cerca de la mitad de la población mundial habita en zonas rurales ${ }^{10}$ y que más de un tercio de la población urbana habita en suburbios, muchos de ellos periurbanos. Sumado a este elemento, la instauración de derechos campesinos y de habitantes rurales, contiene en su seno cuestiones de suma relevancia para la reproducción de la humanidad en su conjunto, en un contexto de riesgo global en que la crisis ambiental y alimentaria se vuelven estructurales (Rubio, 20I3; Holt-Giménez y Patel, 20I2; Vanhaute, 20II) y emergen precisamente de los procesos de mercantilización de la tierra, el agua y el patrimonio biogenético. En estos términos, en la lucha por el establecimiento de una convención internacional de derechos campesinos, se hace patente la identificación del internacionalismo campesino con los intereses más amplios de la humanidad.

Io. Según la ONU y la FAO, el año 2007 por primera vez la población mundial urbana superó a la rural, en una tendencia que deberá mantenerse para llegar a una proporción 60-40 al año 2030, cifras que comparte a su vez el FMI. Dentro de estas cifras cabe destacar además que por primera vez durante el 201 2, China -la segunda economía mundial- informó que su población urbana llegó al 5 I,27\%. 
Respecto de este último punto, en febrero de 2015, el Grupo de Trabajo sobre los Derechos Campesinos que agrupa a las organizaciones civiles que trabajan en la ONU por la declaratoria, ${ }^{11}$ emitió un comunicado conjunto en el que se señalaba:

Nosotras y nosotros, como representantes de mujeres y hombres campesinos, pueblos indígenas, pastores trashumantes, pescadores y trabajadores rurales, debemos ser reconocidos como parte legítima de la cooperación internacional en relación a la alimentación y al desarrollo rural, puesto que somos el principal grupo de la población que se enfrenta al hambre y a la malnutrición, a la vez que contribuimos sobremanera a la alimentación del mundo [...] Entendemos los desafíos actuales a los que se enfrenta el sistema alimentario mundial, y tenemos ideas para una solución. $^{12}$

\section{Antropología y luchas del internacionalismo campesino}

La globalización neoliberal, a través de la ampliación de los marcos de derecho en el plano internacional, ha abierto un terreno de oportunidad política para la constitución de nuevos sujetos de derecho y, consecuentemente, ha propiciado la participación de estos nuevos sujetos en pro del reconocimiento, el respeto y/o la ampliación de sus derechos. Contradictoriamente, al mismo tiempo que se abre esta oportunidad política, se fija la acción colectiva al marco de la gobernabilidad neoliberal, en que lo reconocido o lo viable de reconocer como derecho se transforma en el límite de lo posible para la acción política

I I. Además de Vía Campesina, entre estas organizaciones están: la Unión Internacional de Trabajadores de la Alimentación, Agrícolas, Hoteles, Restaurantes, Tabaco y Afines (UITA), el Foro Mundial de los Pueblos Pescadores (WFFP), la Alianza Mundial de Indígenas Trashumantes (WAMPI), el Consejo Internacional de Tratados Indios (CITI), la Federación Internacionales de Movimientos Adultos Rurales Cristianos (FIMARC), Centre Europe-Tiers Monde (CETIM), FIAN Internacional y el Centro de Estudios Legales y Sociales (CELS).

I2. Ginebra: Declaración conjunta del Grupo de Trabajo sobre Derechos Campesinos, I9 de febrero de 2015 , disponible en <http://viacampesina.org/es/index.php/temas-principales-mainmenu-27/derechos-humanos-mainmenu-4o/recursos-sobre-losderechos-de-los-campesinos/2334-declaracion-conjunta-sobre-derechos-campesinos $>$. 
colectiva. En este sentido, los derechos aparecen como discursos regulatorios que normalizan ciertas relaciones de poder y desfavorecen el desarrollo de demandas políticas radicales, neutralizándolas en el marco del legalismo liberal.

John y Jean Comaroff (20II) han señalado la emergencia de un fetichismo de la ley que redunda en un paulatino desplazamiento de lo político hacia el terreno de lo jurídico. Bajo las condiciones actuales, la decisión de quién tiene derecho y a qué se tiene derecho, se concibe ahora como algo ajeno a la política que se administra según un conjunto de principios jurídicos. Según estos autores, los debates otrora desarrollados en los parlamentos y las protestas callejeras, ahora se desenvuelven en un terreno paralelo que se expande cada vez más. Esto último, que denominan guerra jurídica, es una dimensión endémica de la tecnología de la gobernanza moderna pero, pese a ello, los movimientos sociales parecieran confiar cada vez más en el potencial subversivo de esta estrategia.

Si bien el desplazamiento al que apuntan los autores es una parte constitutiva de la política contemporánea y del modo de encauzar y, muchas veces, neutralizar las demandas de los movimientos sociales, no es menos cierto que han sido los propios movimientos y sus luchas las que han logrado ir más allá de los principios individualistas y liberales que el modelo estampa en su legislación. En cierto sentido, demandas como la de Vía Campesina desafían el límite de lo posible frente a las sólidas neoregulaciones en las que se fundamenta el régimen alimentario actual.

Es preciso apuntar que la vía jurídica es uno de los campos de lucha de Vía Campesina, no el único. La diversidad de agrupaciones que forman parte del movimiento dan cuenta de la diversidad de estrategias políticas, dentro de las cuales la movilización social, los paros agrícolas, la acción directa para agilizar repartos agrarios, los boicots a empresas contaminantes y monopólicas de semillas y la educación popular, entre otras, tienen un lugar destacado. Baste en este último punto considerar la histórica acción política diversa del más grande de los movimientos adscritos a Vía Campesina: el Movimiento de los Trabajadores Rurales Sin Tierra de Brasil.

El uso de la narrativa de los derechos humanos, incluyendo los derechos de nueva generación, ha posibilitado que los movimientos sociales articulen sus prácticas en torno a lograr intervenciones favorables de los Estados, considerando los derechos humanos como herramientas para hacer frente a las prácticas de poder. Al mismo tiempo, el discurso de los derechos humanos, al estar validado globalmente, ha servido de base para radicalizar demandas e 
ir más allá de la lógica liberal, tal y como lo han hecho diversos movimientos indígenas para intentar superar el multiculturalismo neoliberal.

La incursión de la antropología en el debate sobre los derechos humanos ha estado cruzada por la tensión entre relativismo y universalismo y, más contemporáneamente, por críticas como la señalada arriba en torno a la reproducción de los sistemas de poder en el discurso de derechos, en el marco de la democracia liberal globalizada. La primera cuestión, pese a no estar totalmente resuelta, ha encontrado alternativas sobre todo en torno a la consideración levistrossiana de la unicidad del hombre y la diversidad de culturas (Devillard y Baer, 20Io), a la vez que ha sido visualizada como una reflexión improductiva y que tiende a anquilosar a la disciplina frente a la vivacidad del avance de las luchas por los derechos y la dinámica que dicha lucha impone a la creación de nuevas realidades políticas en la globalización.

La estrategia de Vía Campesina por el establecimiento de una Convención de derechos campesinos sigue los pasos de los movimientos indígenas (Edelman y Carwil, 20I I) que, pese a la existencia de instrumentos internacionales, como el Convenio I69 de la OIT, buscaron promover en Naciones Unidas una declaración sobre sus derechos, ratificados en 2007. La participación de los antropólogos en torno a la discusión, el ejercicio y la promoción de los derechos indígenas, ha sido significativa. Ha obligado a repensar definiciones disciplinarias en torno a la identidad y la cultura, toda vez que son los propios sujetos los que recurren a éstas para sus luchas y, muchas veces, para justificar prácticas de esencialismo estratégico.

No obstante, para el caso de los derechos campesinos la posibilidad de establecer sinergias entre el pensamiento antropológico y el movimiento campesino no es tan evidente como ha sido en el caso de los pueblos indígenas. En este punto vuelve a manifestarse la idea del campesinado como objeto incómodo. No es fácil encontrar en el debate teórico de la antropología, ni de otras ciencias sociales, el carácter distintivo de los campesinos como una categoría social, cultural y/o económica (Edelman y Carwil, 20I I), que a la vez que les diferencie de la totalidad de la población le agrupe como sector, posible de identificar como sujeto de derecho. En la práctica, el descubrimiento de una condición común tendiente a la conformación de una identidad unificadora (por lo menos en los marcos nacionales) ha estado más vinculado a un ejercicio histórico de formación político-clasista, que a los principios sustantivos con los que la antropología concibió clásicamente a la cultura y con ello, por ejemplo, a la conformación de los pueblos indígenas como sectores diferenciables. 
Frente a la dificultad para descubrir el carácter distintivo y definitorio de lo que es ser campesino, más aún en el contexto de la globalización neoliberal, la alternativa del movimiento campesino en la lucha por sus derechos se puede presentar en dos ámbitos. El primero, en asumir una definición de lo campesino que supera los esencialismos identitarios o productivistas y que asume en su seno elementos que acercan la definición del campesinado a entenderle como modo de vida y como clase, en el marco de su contradicción con las políticas neoliberales que conculcan sus derechos y le expolian de las bases materiales para su reproducción. En torno a esta última cuestión, se encuentra el segundo ámbito unificador que les visualiza como sector diferenciado.

Más allá de su diversidad, al ser un sector globalmente afectado en su modo de vida y en su reproducción por la actual fase de acumulación, el campesinado emerge como un grupo altamente vulnerable y que requiere por tanto de prácticas de reconocimiento y protección. Tal y como han hecho los indígenas, las mujeres u otros grupos definidos como «vulnerables», en lugar de usar este argumento desde la lógica de la victimización, lo han empleado desde la lógica de la resistencia que les permite visualizarse como iguales y con ello a conformar proyectos comunes (Edelman y Carwil, 20II).

En este ámbito, la actual lucha de Vía Campesina se plantea también en el nivel de la identidad y de los sentidos de los conceptos. El esfuerzo por definir «quiénes son los campesinos» y con ello definir una identidad y un proyecto político y económico alternativo al del globalismo neoliberal, es una tarea que vienen desarrollando los movimientos campesinos y que se expresa también en la lucha por sus derechos.

José Bengoa, miembro del Grupo de Redacción y encargado de la presentación del documento final sobre derechos campesinos, ha reconocido que en gran medida el texto preliminar aprobado en el Comité Consultivo es básicamente el proveniente de Vía Campesina y, por tanto, tiene el valor de haber sido elaborado por las bases que le componen. ${ }^{13}$ Esta cuestión, junto a dar cuenta de la capacidad organizativa y política de Vía Campesina, expresa además su capacidad en tanto movimiento social transnacional para pensar, definir y representar a las poblaciones campesinas.

Pensar lo campesino y sus derechos en el contexto de las actuales contradicciones globales, ha obligado a las organizaciones a trascender las definiciones

I3. Véase <http://www.lemondediplomatique.cl/Declaracion-Internacional-de-los. html>. 
normativas y sustantivas que desde las ciencias sociales otrora se elaboraron para definirles. Así también, su esfuerzo por aproximarse a una definición global y estructural, que asume la diversidad, da cuenta de su distancia con las aproximaciones particularistas que en contraposición a las definiciones clasistas se desarrollaron con la predominancia de los estudios posmodernos y posestructuralistas. Asimismo, con la consideración de la diversidad y de dimensiones culturales e identitarias en la definición de los campesinos, sus intereses y los elementos bases para su reproducción, se trasciende también a planteamientos que han operado desde el reduccionismo clasista.

La diversidad intrínseca del campesinado, tanto en términos socioculturales como socioeconómicos, hace difícil la tarea de pensarle desde las clásicas definiciones antropológicas de cultura e identidad que le conceptualizan como sistema o de las posmodernas que le entienden en constantes procesos de hibridación. Pareciera más pertinente un abordaje gramsciano que le entienda como parte integrante de lo que es ser campesino, una mezcla de elementos, discursos, prácticas e ideas que adquieren sentido en las relaciones de poder y en la experiencia de un grupo de personas con condiciones materiales similares y en contextos históricos determinados. En este sentido, una expresión de la identidad y cultura campesina contemporánea son los proyectos que tienen en su base la necesidad de defender lo particular y, a la vez de trascenderle, como forma de reconocerse en el sistema y posibilitar con ello estrategias políticas para su reproducción como sector. Vía Campesina, en tanto escenario y actor, sería una expresión concreta de dicho proyecto.

La Vía Campesina, como movimiento social transnacional (Edelman, 2007; Borras, Edelman y Kay, 2008; Martínez y Rosset, 2013), ha asumido en su seno la diversidad y ha logrado construir unidad. La dimensión de unidad en la diversidad no sólo se expresa en su condición de escenario de múltiples movimientos («movimiento de movimientos»), sino que igualmente puede ser visualizada en la centralidad que ha adquirido en Vía Campesina el enfoque de género, la dimensión medioambiental y las luchas de reconocimiento. ${ }^{14} \mathrm{Al}$ mismo tiempo, la diversidad constitutiva del movimiento expresa la unidad constituyente de los agraviados por la nueva fase de acumulación capitalista, de-

I4. La dimensión de la lucha por las políticas de reconocimiento está presente, por ejemplo, al interior de la Coordinadora Latinoamericana de Organizaciones Campesinas (CLOC-Vía Campesina), en donde las identidades indígenas y afrodescendientes han cobrado un lugar central en la identidad política y en la agenda de la coordinadora. 
velando con ello tanto el proyecto de clase del neoliberalismo (Harvey, 2007), como las nuevas dimensiones de clase global que adquiere el campesinado.

La propuesta de Vía Campesina recogida por la resolución A/HRC/2 I/L23 de la ONU, pareciera tener presente la dualidad entre la unicidad y la diversidad del campesinado. Su articulado define al campesinado y a las demás personas que viven y trabajan en zonas rurales, y entrega derechos respecto de su relación con el medioambiente, su lugar en el mercado y su asociación política. En el espíritu de la resolución y en la demanda campesina que la sustenta, se condensan gran parte de los avances que otrora la antropología, la sociología rural y otras ciencias sociales, lograron articular en su esfuerzo por entender a las sociedades campesinas y su relación con el capitalismo, pero a la vez suma otros elementos propios del actual momento histórico, como son la identidad cultural, la soberanía alimentaria, la reforma agraria popular, la producción campesina de alimentos, el precio justo, el derecho sobre la propiedad intelectual, entre otros aspectos.

\section{Antropología y campesinado: La pertinencia de lo persistente}

Como señalasen Marx y Engels, «las ideas de la clase dominante son las ideas dominantes en cada época» (1994: 56). Desde esta premisa pienso tanto el epígrafe de Kearney en torno al concepto del campesinado en la antropología, como su expulsión del imaginario social en el contexto neoliberal. Como quedó señalado en este artículo, los años noventa, década dorada para la hegemonía neoliberal, coincidieron con el más importante reflujo del movimiento campesino en el plano de las luchas políticas nacionales y, al mismo tiempo, con el ocaso de los estudios campesinos en la disciplina. Pero paralelamente, en dicha década comienza a cristalizarse el internacionalismo campesino como principal estrategia del campesinado frente al globalismo neoliberal.

En la actualidad, los campesinos a la vez que disputan territorios materiales para su reproducción, demuestran disputar globalmente territorios simbólicos y políticos para definirse y reproducirse en el plano simbólico, exigiendo a su vez a las ciencias sociales dar un paso desde una sociología de las ausencias a una sociología de las emergencias (Santos, 2007)..$^{15}$

I 5. Al concentrarnos en la antropología y, particularmente, en las expresiones teóricas dominantes de la misma, en el presente artículo no consideramos abordajes que, desde el pensamiento inter o transdisciplinario, han sido fundamentales para mantener 
La persistencia de la clase incómoda plantea la necesidad de pensar quiénes la componen, cómo se autodefinen y, desde allí, cómo luchan por su reproducción y por la transformación de las estructuras que les excluyen. El avance de la lucha global por el establecimiento de derechos campesinos constituye un avance en este sentido, a contrapelo de la academia, que volvió al campesinado un sector y categoría obsolescente.

Las luchas del internacionalismo campesino por el reconocimiento de sus derechos, más que arrastrarnos al debate de la potencialidad o la inocuidad de los derechos humanos para lograr verdaderas o radicales transformaciones, debe entenderse como un nuevo espacio político abierto por el propio movimiento campesino que, frente al despojo neoliberal, ha logrado articular en dicha lucha cuestiones que son vitales no únicamente para que podamos seguir contando con campesinos y campesinas, sino que son elementales para la reproducción de la humanidad en su conjunto.

Tal y como fueron sus luchas anticoloniales, reformistas y revolucionarias del siglo pasado, las que en diferentes momentos obligaron a la antropología a voltear su mirada al campo e hicieron al campesinado un objeto incómodo pero pertinente para la disciplina, hoy es el internacionalismo campesino y sus conquistas, los que exhortan a la disciplina a superar las definiciones fragmentarias y, sobre todo, la exclusión del campesinado de las agendas de investigación disciplinaria. La persistencia del campesinado en términos materiales y, sobre todo, sus luchas por recrearse frente al neoliberalismo, esbozan la pertinencia de este sujeto-objeto en la ciencia de la diversidad cultural, de la cual los campesinos del mundo son un bastión imprescindible.

\section{Referencias}

AKram-Lodhi, H. y C. Kay (20I0). «Surveying the agrarian question (part 2): current debates and beyond». Journal of Peasant Studies, 37 (2).

Araghi, F. (2009). "The Invisible Hand and the Visible Foot: Peasants, Dispossession and Globalization». En A. Haroon Akram-Lodhi y Cristobal Kay, Peasants and Globalization: Political Economy, Rural Transformation and the Agrarian Question. Nueva York: Routledge.

viva la reflexión sobre las poblaciones campesinas, así como para documentar y acompañar sus luchas en el contexto de la globalización neoliberal. Entre estas perspectivas pueden inscribirse la agroecología y los estudios agrarios críticos. 
Banco Mundial (2008). Informe sobre el Desarrollo Mundial 2008: Agricultura para el Desarrollo. Washington, D.C., US. Consultado 30 jul. 2013. Disponible en <http://bit.ly/I $5 \mathrm{GF}_{3} 2 \mathrm{c}>$.

BARTRA, A. (2006). El capital en su laberinto. De la renta de la tierra a la renta de la vida. México: Itaca.

Bello, W. (2012). Food Wars. Crisis alimentaria y politicas de ajuste estructural. Barcelona: Virus Editorial.

Bernstein, H. (2OII). «A dinâmica de classe do desenvolvimento agrário na era da globalização». Sociologias, I3 (27).

-. (2012). Dinámicas de clase y transformación agraria. México: Miguel Ángel de Purrúa, Universidad Autónoma de Zacatecas.

-. (2OI4). «Food sovereignty via the 'peasant way': a sceptical view». Journal of Peasant Studies, 4I (2).

Bidaseca, K. (2006). "Disputas culturales y políticas en torno a la/s campesina/os sin tierra en Argentina». VII Congreso Latinoamericano de sociología rural: La Cuestión Rural en América Latina: Exclusión y Resistencia Social. Borón, A. (2008). Socialismo del siglo XXI. ¿Hay vida después del neoliberalismo? Buenos Aires: Luxemburg.

Borras, S. (2004). La Via Campesina, un movimiento en movimiento. Ámsterdam: Transnational Institute y Fundación de Investigaciones Marxistas.

Borras, S., M. Edelman y C. Kay (2008). Transnational Agrarian Movements: Origins and Politics, Campaigns and Impact. Journal of Agrarian Change, 8 (2-3).

Caldeira, T. P. (1989). Antropologia e poder: Uma Resenha de Etnografias Americanas Recentes. BIB, Río de Janeiro, 27: 3-50.

Comaroff, J. L. y J. Comaroff (20II). Etnicidad S. A. Buenos Aires, Madrid: Katz.

Comas, D’Argemir, D. (1998). Antropología económica. Barcelona: Ariel.

De Schutter, O. (2010). Los países combaten el hambre desde el derecho a la alimentación. Disponible en <http://www2.ohchr.org/english/issues/food/ docs/Briefing_Note_oI_May_20IO_SP.pdf>.

Desmarais, A. (2008). La Vía Campesina: La globalización y el poder del campesinado. Barcelona: Editorial Popular.

Devillard, M. y A. Baer (2010). Antropología y Derechos Humanos: multiculturalismo, retos y resignificaciones. Universidad Complutense de Madrid, Revista de Antropología Social, 25.

Edelman, M. (2005). Bringing the Moral Economy back in ... to the Study 
of 2 Ist-Century Transnational Peasant Movements. American Anthropologist, $\operatorname{I07}(3)$.

-. (2007). Los movimientos campesinos transnacionales: éxitos y retos, paradojasy perspectivas, XII Congreso de Antropología en Colombia, Bogotá, Octubre.

-. (20I4). Food sovereignty: forgotten genealogies and future regulatory challenges. En: Journal of Peasant Studies Vol. 4I, No.6, January 20I4 .

Edelman, M. y J. Carwil (20I I). Peasants' rights and the UN system: quixotic struggle? Or emancipatory idea whose time has come? The Journal of Peasant Studies Vol. 38, No. I, January 20 I I.

Escobar, A. (2007). La invención del Tercer Mundo. . Caracas: Fundación Editorial El Perro y la Rana.

Fairbairn, M. Fox, J. Ryan, I. Levien, M. Peluso, N. Razavi, S. ScooNes, I. Sivaramakrishnan (20I4). Introduction: New directions in agrarian political economy. Journal of Peasant Studies, 4I (5). Special Issue: Global Agrarian Transformations. Volume I: New Directions in Political Economy.

FAO, Cepal, ICCA (20I4). Perspectivas de la agricultura y del desarrollo rural en las Américas: una mirada hacia América Latina y el Caribe. Santiago: FAO-Cepal-ICCA.

Geertz, C. (I96I). «Studies in peasant life: Community and society». Biennial Review of Anthropology, 2.

Harvey, D. (2007). Breve historia del neoliberalismo. Madrid: Akal.

Heynig, K. (I982). «Principales enfoques sobre la economía campesina». Revista de la Cepal, I6: I I 5-I42.

Holt-Giménez, E. y R. Patel (20I 2). ¡Rebeliones alimentarias! La crisis y el hambre por la justicia. México: Miguel Ángel Porrúa.

IzCARA, S. (20I2). La era de la post-globalización. El retorno de los ciclos agrarios. México: Universidad Autónoma de Tamaulipas, Miguel Ángel Purrúa.

KaustKy, K. (2002 [1 899]). La cuestión agraria. México: Siglo XXI.

KeARney, M. (I996). Reconceptualizing the peasantry, antropology in global perspective. California: WestviewPress.

Marx, C. y F. Engels (I994). La ideología alemana. Barcelona: Grijalbo.

Martínez, M. y P. Rosset (2013). «Del conflicto de modelos para el mundo rural emerge la Vía Campesina como movimiento social transnacional». En El Otro Derecho, 44. 
Mintz, S. (I996). Dulzura y poder. México: Siglo XXI.

Moyo, M., P. Jha y P. Yeros (2013). The Classical Agrarian Question: Myth, Reality and Relevance Today. Agrarian South: Journal of Political Economy, 2 (3).

Owen, J. (2005). «In defense of the peasant». Journal of Contemporary Asia, 35:382-402.

Palerm, Á. (2008). Antropología y marxismo. México: CIESAS.

Pérez-Vitoria, S. (20Io). El retorno de los campesinos. Barcelona: Icaria.

Perspectivas. Ponencia presentada en el seminario ¿Quiénes son los campesinos hoy?: Diálogos en torno a la antropología y los estudios rurales en Colombia, coordinado por Nadia Rodríguez (U. del Rosario) y Juana Camacho (ICANH), XII Congreso de Antropología en Colombia, Universidad Nacional de Colombia, Bogotá 2007.

Ploeg, van der J. (2010). Nuevos campesinos. Campesinos e imperios alimentarios. Barcelona: Icaria.

Rodríguez, F. (20I0). «Regímenes, sistema y crisis agroalimentaria». En El Otro Derecho, 42.

Rosset, P. y M. Martínez-Torres (2013). La Via Campesina y agroecología. Edición digital libro abierto de la Vía Campesina. Disponible en $<$ http:// viacampesina.org/downloads/pdf/openbooks/ES-o9.pdf>.

Rubio, B. (2006). «Exclusión rural y resistencia social en América Latina.» Revista ALASRU Nueva Época, 4.

-. (2012). Explotados y excluidos. Los campesinos latinoamericanos en la fase agroexportadora neoliberal. México: Plaza y Valdez.

-. (20I3). "La crisis alimentaria en el corazón de la crisis capitalista mundial». En B. Rubio (coord.), La crisis alimentaria mundial: impacto sobre el campo mexicano. México: UNAM, Instituto de Investigaciones Sociales, Miguel Ángel Porrúa.

Santos, B. (2007). Conocer desde el Sur. Para una cultura política emancipatoria. La Paz: Clacso, CIDES-UMSA, Plural Editores.

Stavenhagen, R. (1969). Las clases sociales en las sociedades agrarias. México: Siglo XXI.

Vanhaute, E. (20II). «From famine to food crisis: what history can teach us about local and global subsistence crises». Journal of Peasant Studies, 38 : I.

Viola, A. (2000). «Introducción: La crisis del desarrollismo y el surgimiento de la antropología del desarrollo». En A. Viola, Antropología del desarrollo, teorías y estudios etnográficos en América Latina. Barcelona: Paidós. 


\section{Sobre el autor}

Raúl Contreras es antropólogo por la Universidad Católica de Temuco, Chile. Maestro en antropología por la Universidad Nacional Autónoma de México y doctorante en la misma casa de estudios. Su correo electrónico es $<$ raulantu@gmail.com>. 
